\title{
DESEMPENHO DOS PROFISSIONAIS DE SAÚDE NO ACOMPANHAMENTO DOS CASOS DE TUBERCULOSE NO AMBIENTE PRISIONAL
}

\section{PERFORMANCE OF HEALTH PROFESSIONALS IN FOLLOW-UP OF TUBERCULOSIS CASES IN THE PRISON ENVIRONMENT}

Lívia Menezes Borralho ${ }^{1}$

Rosiane Davina da Silva ${ }^{2}$

Aguinaldo José de Araújo ${ }^{3}$

Bueno Callou Bernardo de Oliveira ${ }^{4}$

Sheylla Nadjane Batista Lacerda ${ }^{5}$

Tânia Maria Ribeiro Monteiro de Figueiredo ${ }^{6}$

RESUMO: OBJETIVO: Este estudo objetivou detalhar a prática dos profissionais de saúde quanto ao acompanhamento dos casos de tuberculose no ambiente prisional. MÉTODOLOGIA: Estudo descritivo com abordagem qualitativa, realizado em 06 unidades penitenciárias de um estado do Nordeste brasileiro. Os dados foram coletados no período de julho de 2017 a janeiro de 2018 através de entrevista estruturada áudio gravada, e foram analisados a luz da hermenêutica dialética. RESULTADOS: Foram entrevistados 28 profissionais das Equipes de Saúde Prisional. Como resultados, foi possível constatar a dificuldade dos profissionais de saúde de fazerem até mesmo um simples contato com os doentes encarcerados, de forma que percebe-se nos relatos o acompanhamento incipiente dos casos, com raros encontros entre os membros da equipe e o doente de tuberculose. Nas falas também é possível observar que muitas vezes a responsabilidade pelo acompanhamento do caso é repassada aos Agentes Penitenciários ou para os presos de bom comportamento, contudo não é plausível que estes promotores da saúde desempenhem o papel das Equipes de Saúde Prisional. CONCLUSÃO:

\footnotetext{
${ }^{1}$ Mestre em Saúde Pública pela Universidade Estadual da Paraíba. E-mail: buenocallou@gmail.com.

2 Mestre em Saúde Pública pela Universidade Estadual da Paraíba. E-mail: rosianedavina@hotmail.com.

3 Mestre em Saúde Pública pela Universidade Estadual da Paraíba. E-mail: aguinaldo.araujo@hotmail.com.

${ }_{5}^{4}$ Mestre em Saúde Pública pela Universidade Estadual da Paraíba. E-mail: buenocallou@gmail.com.

5 Professora Doutora Diretora Pedagógica da Faculdade Santa Maria. E-mail: sheyllabatista@bol.com.br.

${ }^{6}$ Professora Doutora do curso de Pós-Graduação em Saúde Pública da Universidade Estadual da Paraíba. E-mail: taniaribeiro@ccbs.uepb.edu.br.
} 
Conclui-se que, apesar de muitos profissioanis de saúde deterem conhecimento satisfatório sobre as ações de controle da tuberculose, na prática o acompanhamento dos casos da doença no ambiente prisional encontra-se muito distante do preconizado, de maneira que a alta demanda de atendimentos de casos agudos, e as instáveis condições de segurança para quem trabalha nos presídios, foram referidas como as principais dificuldades para realizar 0 devido acompanhamento do doente de tuberculose no ambiente prisional.

Palavra chave: Assistência de Saúde. Equipe de Saúde. Prisões. Tuberculose. Vigilância Epidemiológica.

ABSTRACT: OBJECTIVE: This study aimed to detail the practice of health professionals regarding the monitoring of tuberculosis cases in the prison environment. METHODOLOGY: Descriptive study with a qualitative approach, carried out in 06 penitentiary units in a state in the Northeast of Brazil. Data were collected from July 2017 to January 2018 through a structured audio recorded interview, and were analyzed in the light of dialectical hermeneutics. RESULTS: 28 professionals from the Prison Health Teams were interviewed. As a result, it was possible to see the difficulty of health professionals to make even a simple contact with incarcerated patients, so that the reports show the incipient monitoring of cases, with rare encounters between team members and the patient. tuberculosis. In the speeches it is also possible to observe that the responsibility for monitoring the case is often passed on to Prison Agents or to prisoners of good behavior, however it is not plausible that these health promoters play the role of the Prison Health Teams. CONCLUSION: It is concluded that, despite the fact that many health professionals have satisfactory knowledge about tuberculosis control actions, in practice the monitoring of cases of the disease in the prison environment is very far from the recommended, so that the high demand for acute case visits, and the unstable safety conditions for those who work in prisons, were mentioned as the main difficulties in carrying out the proper monitoring of tuberculosis patients in the prison environment.

KEYWORD: Health Assistance. Health Team. Prisons. Tuberculosis. Epidemiological monitoring. 


\section{INTRODUÇÃO}

A crescente taxa de ocupação prisional, sem a adequação sincrônica de estrutura física e de recursos humanos, somada às condições precárias de higiene, ventilação e iluminação solar nas celas, compõem o cenário ideal para disseminação do Mycobacterium tuberculosis (SOUZA, 2012). O risco das pessoas privadas de liberdade (PPL) adoecerem por tuberculose (TB) é 28 vezes maior quando comparado ao risco de adoecimento da população em geral (BRASIL, 2019).

Nos últimos anos a população carcerária brasileira tem aumentado drasticamente, e este fato tem contribuído preponderantemente para fragilização das ações de controle da TB dentro dos presídios (MOREIRA, 2019; SACRAMENTO, 2017).

A taxa de ocupação nos presídios brasileiros é de 197,4\%, o que representa um déficit total de 358.663 mil vagas. O estado da Paraíba ainda apresenta uma taxa de ocupação superior a do país, alcançando um índice de $217,1 \%$, excedendo assim o dobro da capacidade do sistema prisional do estado (BRASIL, 2016).

As circunstâncias que permeiam as altas prevalências da TB no ambiente prisional provocam impactos que não se limitam as PPL, apresentando potencial para afetar os familiares, funcionários, guardas, e, por conseguinte, a população livre (MOREIRA, 2010; SACCHI, 2015). Diversos são os obstáculos que dificultam o controle da TB no sistema prisional, que podem variar desde as questões genéricas relacionadas à infra-estrutura, organização e funcionamento da instituição prisional, quanto á questões específicas como a insuficiência da capacidade laboratorial para diagnóstico, interrupções no fornecimento de medicamentos, medidas inaquadas de controle da infecção, baixa prioridade para o combate à doença na prisão, dentre outros (COSTA, 2014; MOREIRA, 2019).

De acordo com o segundo pilar da estratégia da Organização Mundial de Saúde (OMS) para prevenção, cuidado e controle da TB após 2015, os prisioneiros fazem parte dos grupos vulneráveis à TB, e dessa forma, o combate à doença nessa 
população deve ser priorizado (WHO, 2013). No Brasil, com o objetivo de ampliar as ações de saúde do Sistema Único de Saúde (SUS) para a PPL, o Ministério da Saúde (MS) lançou em 2014 a Política Nacional de Atenção Integral à Saúde das Pessoas Privadas de Liberdade no Sistema Prisional (PNAISP), que traz como uma das diretrizes, uma linha de ação específica para o enfrentamento da TB (BRASIL, 2014; MACEDO, 2020).

A garantia do acesso das PPL às ações e serviços de saúde no âmbito do SUS constitui uma responsabilidade partilhada pelo Ministério Extraordinário da Segurança Pública (MESP) com o Ministério da Saúde, e sua concretização implica a efetiva parceria entre as secretarias de justiça/ administração penitenciária e de saúde, nos níveis estadual e municipal, sendo imprescindível que as Equipes de Saúde Prisional (ESP) tenham autonomia para definição das ações, e que tenham segurança para prestar os cuidados necessários (LERMEN, 2015; VITTI JÚNIOR, 2013).

O Programa de Controle da Tuberculose (PCT) propõe estratégias desafiadoras que podem contribuir na organização do processo de trabalho das ESP. Recomenda-se: busca ativa do sintomático respiratório, que deve ser realizada no momento do ingresso, entre os contatos e como rastreamento de massa; diagnóstico da TB por meio do TRM-TB em substituição à baciloscopia; testagem para o HIV a todas as PPL com diagnóstico de TB; realização anual da prova tuberculínica em todas as pessoas vivendo com HIV (PVHIV) privadas de liberdade; Tratamento Diretamente Observado (TDO) e realizado exclusivamente por profissionais de saúde; assegurar a continuidade do tratamento após o livramento (BRASIL, 2014, 2019).

Dessa forma, face aos obstáculos que dificultam a assistência à saúde no sistema prisional, considerando a necessidade de ampliar as investigações sobre os aspectos que permeiam o fazer no ambiente carcerário, com vistas a colaborar na proposição de estratégias que possam subsidiar gestores e profissionais das instituições na perspectiva de efetivar as ações de controle da TB, o presente estudo objetivou detalhar a prática dos profissionais de saúde quanto ao acompanhamento dos casos de TB no ambiente prisional. 


\section{METODOLOGIA}

Estudo descritivo com abordagem qualitativa, realizado em 06 unidades penitenciárias (UP) de um estado do Nordeste brasileiro. As UP incluídas no estudo ficam localizadas nas duas maiores cidades do estado, sendo uma delas a capital, e foram selecionadas previamente por englobarem a maior parte dos casos de TB notificados no sistema carcerário estadual.

Participaram do estudo todos os profisisonais das ESP, sendo a acessibilidade e a indisponibilidade os fatores que interferiram no quantitativo da amostra. Para a coleta dos dados foi aplicado um roteiro estruturado contendo as seguintes perguntas: como são realizadas as ações de tuberculose na unidade penitenciária; fale sobre a rotina de avaliação de saúde quando o privado de liberdade ingressa nesta unidade penitenciária. Com o consentimento dos participantes as entrevistas foram gravadas, e tiveram duração média dez minutos.

A coleta ocorreu no período de agosto de 2017 a janeiro de 2018 nas dependências das UP. As entrevistas foram transcristas na íntegra em um documento Microsoft Word 2010, e após leitura dos discursos, os relatos que tinham referência ao processo de acompanhamento dos casos de TB no ambiente prisional foram agrupados para análise. Os relatos foram analisados à luz da hermenêutica dialética, possibilitando identificar aspectos metafóricos e sociais envolvidos na forma que os sujeitos compreendem sua realidade.

A abordagem na perspectiva da hermenêutica permite compreender o sentido das palavras e identificar os significados contidos na fala, que podem atribuir-se a momentos anteriores. A dialética cria instrumentos para compor o pensamento crítico, considerando as contradições que estão presentes na linguagem, dessa forma permite compreender que analisar os significados das falas deve ser um processo implicado na dinâmica das contradições (MINAYO, 2014, 2016).

A identificação dos profissionais ocorreu utilizando a letra que representa sua categoria profissional (Enfermeiro - E; Médico - M; Assistente Social - AS; Auxiliar de Saúde Bucal - ASB; Cirurgião Dentista - CD; Psicólogo - P; Técnico de Enfermagem 
- TE) e o algarismo arábico para identificar a UP, variando de 01 a 06, especificando assim as ESP que foram entrevistadas.

O presente estudo fez parte do projeto de pesquisa intitulado "A tuberculose e a coinfecção TB-HIVIAIDS na População Privada de Liberdade", aprovado pelo Comitê de Ética e Pesquisa sob o Parecer no 52879215.4.0000.5187. Para realização da pesquisa foi solicitada autorização à Secretaria de Administração Penitenciária do Estado da Paraíba.

\section{RESULTADOS E DISCUSSÃO}

Participaram do estudo 28 profissionais de saúde, sendo 06 enfermeiros, 04 cirurgiões dentistas, 06 técnicos de enfermagem, 02 auxiliares de saúde bucal, 05 psicólogos, 04 assistentes sociais e 01 médico. Do total de entrevistados 53,6\% estão nas equipes a mais de quatro anos, e 89,2\% já fizeram algum curso ou atualização sobre TB. Os profissionais entrevistados eram preponderantemente do sexo feminino, representando $82 \%$ da amostra, e quanto a idade, a maioria tinha mais de 40 anos, representando $39 \%$ da amostra.

A análise dos discursos coletados a partir das entrevistas foi estruturada em categorias estabelecidas com base no objetivo do estudo, sendo elas: categoria I - A vivência no acompanhamento dos casos de tuberculose; categoria II - O fazer em situações de transferência durante o tratamento da tuberculose.

\section{Categoria I - A vivência no acompanhamento dos casos de tuberculose}

O tratamento da TB em ambiente prisional baseia-se nos pilares de compromisso político, articulação entre profissionais da saúde e segurança, detecção precoce de casos novos, suprimento regular de medicamentos e ingesta supervisionada, consultas mensais com vistas a evidenciar resposta ao tratamento a 
partir da evolução clínica do paciente, realização das baciloscopias de controle, e manutenção dos sistemas de informação atualizados (BRASIL,2019; VITTI JÚNIOR, 2013).

No acompanhamento dos casos de TB, o vínculo do doente com a equipe é essencial, contudo observou-se fragilidade da ESP em aproximar-se das PPL.

"A maior dificuldade é aquele contato direto, e também influencia no tratamento, porque não há a possibilidade do contato direto [...] aquele contato direto nosso com o paciente, que não tem, num é que não tem, a gente tenta..." (CD04).

Nesta fala, embora que o profissional seja da área de saúde bucal, há a preocupação em referir que o simples contato com o doente ocorre com certa dificuldade. É sabido que a frequência no acompanhamento dos casos de TB é maior para os profissionais médicos e enfermeiros, que deve envolver uma assistência diária, com supervisão da ingesta dos medicamentos, consultas mensais de avaliação, baciloscopias de controle (no mínimo no segundo, quarto e sexto mês de tratamento), aferição do peso e aconselhamento, visando a adesão ao tratamento com estímulo ao autocuidado (BRASIL, 2004, 2006, 2019).

No aspecto de desenvolver o trabalho de forma multidisciplinar para facilitar o melhor acompanhamento dos casos de TB, observou-se divergência na fala de profissionais da mesma equipe.

"a equipe em geral chama os pacientes para fazer as baciloscopias iniciais quanto as de controle, e fazer seu acompanhamento, em média de 15 em 15 dias são chamados para saber como está seu tratamento... e como a gente não tem a capacidade de ir sempre entregar a medicação e outra dificuldade é por facção criminosa, que como são duas diferentes então não tem como ficar nem a gente indo nem eles vindo" (CD03). 
"quando é diagnosticado eles são acompanhados direitinho, principalmente assim a medicação supervisionada, aí fora isso faz a BK de controle... que sempre acompanha, e pronto, caso precise, passe mal, alguma coisa, já é encaminhado para o hospital (hospital de referência para doenças infectocontagiosas)" (TE03).

Nos dois relatos observa-se referência a algumas recomendações do Programa Nacional de Controle da Tuberculose (PNCT), entretanto há divergência quanto a realização da supervisão do tratamento, pois o Técnico de Enfermagem afirma que o TDO é algo vivenciado na sua prática.

Um profissional expôs no seu discurso aspectos preocupantes, os quais impactam negativamente no controle da TB.

"o tratamento, infelizmente a gente não consegue tá com acompanhamento mensal de caso, vendo o paciente, vamos supor de pesar o paciente, vê se ele ganhou mais um pesinho, se ele tá melhor, porque realmente a demanda é muito grande, mas eu ainda consigo fazer o acompanhamento da baciloscopia mensal e o encontro da gente é só quando começa o tratamento e quando ele termina" (E04).

Nesta fala é possível perceber que o profissional preocupa- se por não poder acompanhar o doente como deveria, e mostra conhecimento sobre as ações prioritárias para um melhor seguimento do caso, no entanto, percebe-se que o distanciamento entre o saber e a prática é atribuído a grande demanda existente na UP.

Considerando que o cuidado é um somatório de decisões quanto ao uso das tecnologias e da articulação entre os profissionais para tentar se aproximar de forma adequada das necessidades dos sujeitos, apenas dois encontros, no início e no fim 
do tratamento, não permitem identificar falhas que poderiam ser ajustadas, não sendo possível garantir a adesão ao tratamento, e ainda impossibilitando a contrução do vínculo do apenado com a equipe (BRASIL, 2004, 2006, 2019).

Para outro profissional da mesma ESP, a equipe de Enfermagem realiza o devido acompanhamento dos doentes de TB.

"quando da início ao tratamento é acompanhar, a enfermeira sempre faz esse acompanhamento, vê a história da medicação, se eles estão evoluindo nos sintomas... ela costuma avaliar sempre, faz o teste rápido e muitas vezes eu auxilio também fazendo o pré-teste e pós-teste em todos os de TB" (P04).

Porém as ações que são expostas nesse relato mostram as fragilidades na concepção deste profissional sobre os aspectos do acompanhamento dos casos de TB no ambiente prisional.

No tocante ao tratamento supervisionado, foi dito:

"é impossível a gente fazer uma medicação supervisionada, porque infelizmente a gente não pode estar toda manhã dentro do pavilhão" (TE04).

Relato que expressa uma condição limitante do profissional, provavelmente porquestões relativas a alta demanda de atendimentos de casos agudos, somada as dificuldades frente às questões de segurança, porém "o impossível" referido por este profissional muitas vezes acaba por bloquear as possibilidades de reorganização do processo de trabalho, tendo em vista que a força da expressão não permite espaço para repensar estratégias.

Ainda na perspectiva da supervisão do tratamento da $T B$, considera-se estratégia essencial a inclusão dos Agentes Penitenciários, como também os presos de bom comportamento, na detecção do sintomático respiratório (SR), na garantia do acesso oportuno à equipe, e no apoio constante durante o tratamento. Todavia, 
estes promotores da saúde não podem substituir o papel da ESP, principalmente na função da supervisão do tratamento (BRASIL, 2006, 2019). Percebe-se que essa atribuição ocorre nos presídios a partir do seguinte relato:

"a gente explica a medicação e essa medicação é paga (medicamento entregue ao agente penitenciário ou ao preso de bom comportamento) todo mês" (E05).

Além da função atribuída aos promotores de saúde, observa-se na fala que as orientações acontecem uma vez ao mês, não havendo contato diário com o apenado, no entanto, é válido considerar que esta estratégia apesar de não ser recomendada, é factível na organização do trabalho desta equipe.

Outra questão no acompanhamento dos casos, é não compreender a contraindicação do isolamento respiratório para as PPL com diagnóstico de TB que já estão no convívio intracela, e que não apresentam suspeita de resistência ou falência em tratamento anterior.

"chegando o resultado da baciloscopia se for positivo, aí eles ficam afastado numa cela, durantes dois, três dias... aí eles voltam pra cela, para o convívio deles que eles tinham normal" (TE05).

"se tiver algum caso positivo, começa o tratamento, tem os dias de ficar aqui no isolamento né, até passar o período maior de contágio, depois eles retornam ao pavilhão né, 15 dias na enfermaria..." (P01).

Outra profissional trouxe um contraponto ao isolamento dos casos, que no ambiente prisional, tende a favorecer a adesão ao tratamento da TB. 
"porque até a outra médica já dizia que não adiantava isolar se ele já convivia na cela antes, então se ele tinha que contaminar já tava contaminado" (E05).

O isolamento respiratório dos casos de TB é necessário para os casos identificados no momento do ingresso na prisão, para os casos suspeitos ou confirmados de resistência, e quando ocorre a falência de tratamento. $\mathrm{O}$ isolamento já no convívio intracela não está indicado porque nas semanas que precedem o diagnóstico os contatos já foram largamente expostos, a contagiosidade tende a diminuir rapidamente nas primeiras semanas de tratamento, e o isolamento contribui para estigmatização dos doentes e tende a desestimular a busca pelo diagnóstico por parte de outras PPL pelo temor à discriminação e à limitação de circulação (BRASIL, 2004, 2019).

Nesse contexto, questiona-se a eficiência dos processos de educação permanente, tendo em vista que a maioria destes profissionais participou de qualificações sobre a temática, e ainda assim, insistem em conduzir práticas que não contribuem para o controle da doença.

\section{Categoria II - O fazer em situações de transferência durante o tratamento da tuberculose}

As transferências dos apenados em tratamento de TB entre unidades prisionais devem ser estabelecidas por meio de comunicação rápida, e o presídio receptor deve avaliar o apenado nos primeiros 7 dias, possibilitando assim a continuidade do tratamento sem interromper o uso do medicamento por mais de 30 dias, evitando falhas operacionais, e o possível desfecho por abandono (BRASIL, 2004, 2019).

$\mathrm{Na}$ maioria das equipes observou-se que há uma comunicação, principalmente, por meio de aplicativos de mensagens rápidas e que posteriormente os prontuários são encaminhados para os presídios receptores. 
"A gente mantém contato com as enfermeiras dos outros presídios, se ele vier pra cá e já tá em tratamento, elas mandam pra gente ou via whastapp ou se tiver prontuário, consegue mandar o prontuário pra gente, a gente faz o Sinan de transferência e continua o tratamento" (E04).

Em outro presídio também foi relatado facilidades na comunicação entre ESP.

"Quando ele vem transferido o agente traz pra gente, 'óh tem um problema”, ou a própria equipe da outra unidade já faz um contato direto, pra gente poder dar continuidade ao tratamento" (AS04).

Nos relatos desta equipe percebe-se que o contato entre as ESP parece ser ágil e habitual, além de utilizarem dispositivos de comunicação instantânea para facilitar a comunicação, diminuindo as chances de interrupção do tratamento. Outra preocupação nos casos de transferência, refere-se à comunicação entre os agentes penitenciários, do profissional que transfere o sujeito, com o receptor no presídio de destino, e a comunicação entre Agente Penitenciário e o próprio doente (BRASIL, 2019).

"se for a outro presídio, entraremos em contato com os outros profissionais de lá indicando para que ele continue o tratamento, quando ocasiona da gente não tomar conhecimento de imediato, eles são orientados a procurar logo a equipe de saúde no presídio onde ele for" (AS03).

Desta forma o profissional promove a autonomia do apenado, pois ao orientálo quantoa importância de procurar a equipe de saúde do presídio, colabora para que o doente compreenda que o tratamento não pode ser interrompido. 
"Aí quando o PL (Privado de Liberdade) é transferido para outra unidade a comunicação acontece através das enfermeiras, quem recebe liga, quando nós sabemos para onde ele foi, então, e não tivemos nenhuma comunicação da colega, nós procuramos ligar, mas geralmente elas ligam, recebemos um paciente daí e tudo mais, a gente passa o esquema, isso daí não é problema" (E01).

Observa-se que este profissional atribui a responsabilidade da comunicação à unidade receptora, caso o presídio não identifique a chegada de nenhuma PPL em tratamento de TB, ou considerando que o apenado ao chegar no presídio não informa sua condição de saúde, a continuidade do tratamento fica na dependência de uma comunicação tardia.

Outra questão importante apontada refere-se as transferências de apenados em tratamento sem o prontuário, dificultando a continuidade do acompanhamento no presídio receptor.

"Quando chega uma transferência grande aqui, geralmente os agentes, os chefes de disciplina, eles costumam levantar se tava em tratamento para TB em outra unidade, aí eles repassam pra gente [...] aí a gente costuma se comunicar com as unidades de origem deles para pedir prontuário, porque não tem o costume de mandar, pra fazer esse acompanhamento" (P04).

$\mathrm{Na}$ rotina de transferências de apenados em tratamento de TB a recomendação para facilitar o acompanhamento é enviar o prontuário do doente para que a equipe da unidade receptora possa conduzir o tratamento e providenciar a devida medicação (BRASIL, 2019). 


\section{CONSIDERAÇÕES FINAIS}

O acompanhamento dos casos de TB no ambiente prisional apresenta limitações que se associam a questões múltiplas inerentes ao contexto do encarceramento. Seguir uma rotina no seguimento dos doentes com TB exige organização do processo de trabalho, e depende da viabilidade estrutural, funcional e política da UP.

Neste estudo os profissionais das ESP apresentaram em seus relatos diversas dificuldades quanto ao acompanhamento dos apenados com TB. O tratamento supervisionado e o contato diário com os doentes foram citados como um grande desafio a ser incorporado na prática. Dentre as justificativas, a consideração do ambiente como local de segurança, e a alta demanda de outras condições agudas como prioritárias, são os aspectos mais relevantes apresentados pelos entrevistados.

Compreende-se dessa forma que na condição de aprimorar o TDO como estratégia efetiva no cuidado do doente no presídio, faz-se necessário uma melhor organização das demandas de saúde que chegam as equipes, e ainda, uma reestruturação organizacional que permita atender as demandas programadas e deixe acesso espontâneo para as demandas urgentes, sem que nenhuma sobrecarregue a outra, tendo em vista que a TB no ambiente prisional figura-se como linha de cuidado prioritária e que seu controle é reflexo do trabalho articulado da ESP e dos demais profissionais do presídio.

$\mathrm{Na}$ tentativa de ampliar o alcance das ações das equipes, observou-se a utilização de estratégias que podem contribuir na supervisão do tratamento, no entanto não devem substituir as atribuições dos profissionais da saúde. Entende-se que determinadas condições que podem interromper o tratamento só são percebidas pelos profissionais de saúde, e que a contrução do vínculo entre a ESP e as PPL portadoras de TB é imprecindível para o controle da doença.

Nos discursos de alguns profissionais percebeu-se que a rotina de consultas mensais, 
baciloscopias de controle, acompanhamento da melhora clínica do apenado, nem sempre é vista como essencial para garantir a conclusão do tratamento com sucesso. Essa assistência precária e insuficiente foi observada em algumas unidades do estudo, acabando por permear práticas incompletas ou até mesmo contraindicadas.

Nas medidas de controle da doença, o isolamento respiratório aparece como estratégia para as PPL que já estão ambiente intracela, sem que haja suspeita de resistência ou falência de tratamento. Os profissionais que consideraram essa ação eficaz, ainda não perceberam as consequências do isolamento, o qual contribui para estigmatização dos doentes e tende a desestimular a busca pelo diagnóstico por parte de outras PPL pelo temor à discriminação e à limitação de circulação.

Quanto aos componentes do cuidado para um devido acompanhamento dos casos de TB em situações de transferências, os profissionais, a partir de seus relatos, expressam conhecimento sobre as ações que devem ser feitas na perspectiva de zelar pela continuidade do tratamento da TB das PPL. Os discursos também apontam que há comunicação entre as ESP em caso de transferência dos casos de TB, entretanto muitas vezes esta se dá de forma incipiente.

Dessa forma, conclui-se que, apesar de muitos profissioanis de saúde deterem conhecimento satisfatório sobre as ações de controle da tuberculose, na prática o acompanhamento dos casos da doença no ambiente prisional encontra-se muito distante do preconizado, de maneira que a alta demanda de atendimentos de casos agudos, e as instáveis condições de segurança para quem trabalha nos presídios, foram referidas como as principais dificuldades para realizar o devido acompanhamento do doente de tuberculose no ambiente prisional. 


\section{REFERÊNCIAS BIBLIOGRÁFICAS}

BRASIL, Ministério da Saúde. Secretaria de Atenção à Saúde. Departamento de Ações Programáticas Estratégicas. Área Técnica de Saúde no Sistema Penitenciário. Plano Nacional de Saúde do Sistema Penitenciário. Brasília, 2004.

BRASIL. Ministério da justiça. Conselho Nacional de Política Criminal e Penitenciária. Recomendações para Detecção de Casos de Tuberculose entre ingressos no Sistema Penitenciário. Brasília: Ministério da Justiça; 2006.

BRASIL. Ministério da Saúde. Secretaria de Atenção à Saúde. Departamento de Ações Programáticas Estratégicas. Coordenação de Saúde no Sistema Prisional. Política Nacional de Atenção Integral à Saúde das Pessoas Privadas de Liberdade no Sistema Prisional. Ministério da Saúde, Secretaria de Atenção à Saúde, Departamento de Ações Programáticas Estratégicas, Coordenação de Saúde no Sistema Prisional - 1. Ed - Brasília: Ministério da Saúde, 2014. 60 p.

BRASIL. Ministério da Justiça e Segurança Pública. Departamento Penitenciário Nacional. Levantamento Nacional de Informações Penitenciárias: INFOPEN atualização junho de 2016. Org. Tandhara Santos; Colaboração. Marlene Inês da Rosa, et al. Brasília - DF, 2017, p. 65.

BRASIL. Ministério da Saúde. Secretaria de Vigilância em Saúde. Departamento de Vigilância das Doenças Transmissíveis. Manual de Recomendações para o Controle da tuberculose no Brasil. Brasília: Ministério da Saúde, 2019. Disponível em: < http://www.saude.mg.gov.br/tuberculose.

COSTA, G.M.C. et al. Perfil demográfico e das condições de trabalho: a realidade das equipes de saúde implantadas em unidades prisionais. Rev. Bras. Pesq. Saúde, Vitória, 2014; 16(4): 13-22. Disponível em: https://periodicos.ufes.br/rbps/article/view/11169/7779.

GRABOIS, V. Gestão do cuidado. Cap. II, pg 153. Qualificação de gestores dos SUS. 2 ed. rev. ampl. Rio de Janeiro, Ensp, 2011.

LERMEN, H. S. et al. Saúde no cárcere: análise das políticas sociais de saúde voltadas à população prisional brasileira. Revista de Saúde Coletiva, Rio de Janeiro, 25 [ 3 ]: 905-924, 2015. Disponível em: https://scielosp.org/pdf/physis/2015.v25n3/905-924/pt.

MACEDO, L. R.; MACIEL, E. L. N.; STRUCHINER, C. J. Fatores associados à tuberculose na população privada de liberdade no Espírito Santo. Rev Saude Publica. 2020;54:67 Disponível em: https://www.scielo.br/pdf/rsp/v54/pt_1518-8787-rsp-54-67.pdf.

MERHY, E. E. A perda da dimensão cuidadora na produção da saúde: uma discussão do modelo assistencial e da intervenção no seu modo de trabalhar assistência. In: O SUS em Belo Horizonte: reescrevendo o público. São Paulo, Ed. Xamã; 1998.

MINAYO, M.C.S. Hermêutica dialética. In: Minayo, MCS; Deslandes, SF; Organizadores. O desafio do conhecimento: pesquisa qualitativa em saúde. $14^{a}$ edição. Rio de Janeiro: Fiocruz, 2014. p. 327-350.

MINAYO, M.C.S. Métodos, técnicas e relações em triangulação. In: Minayo, MCS; Organizadores. Avaliação por triangulação de métodos: abordagem de programas sociais. Rio de Janeiro: Fiocruz, 2016. p. 71-104. 
MOREIRA, T.R; ETHEL, J.L.F.; MACIEL, L.N. Tuberculose no sistema prisional capixaba. Revista Brasileira de Pesquisa em Saúde 2010; 12(1):26-33.

MOREIRA, T. R. Et al. Prevalência de tuberculose na população privada de liberdade: revisão sistemática e metanálise. Rev Panam Salud Publica 43, 2019. Disponível em: https://scielosp.org/pdf/rpsp/2019.v43/e16/pt.

SACRAMENTO, D. S.; GONÇALVES, M.J.F. Situação da tuberculose em pessoas privadas de liberdade no período de 2007 a 2012. Rev enferm UFPE on line, Recife, 2017; 11(1):140- 51.

SACCHI, F. P. C. Et al. Prisons as Reservoir for Community Transmission of Tuberculosis, Brazil. Emerging Infectious Diseases, Vol. 21, No. 3, March 2015. DOI: http://dx.doi.org/10.3201/ eid2103.140896.

SOUZA, K. M. J. et al. Atraso no diagnóstico da tuberculose em sistema prisional: a experiência do doente apenado. Texto Contexto Enferm, 2012; 21 (1):17-25. Disponível em: https://www.scielo.br/pdf/tce/v21n1/a02v21n1.pdf.

VITTI JUNIOR, W. O Controle da Tuberculose nos Presídios: Atuação das Equipes de Saúde na Região (DRS VI) de Bauru/SP. [Dissertação]. Botucatu: Faculdade de Medicina. Universidade Estadual Paulista, 2013.

WHO. Global strategy and targets for tuberculosis prevention, care and control after. 2015 [Internet]. Geneva: World Health Organization; 2013 [cited 2017 May 26]. 2 p. Disponível em: https://www.who.int/tb/strategy/End_TB_Strategy.pdf. 